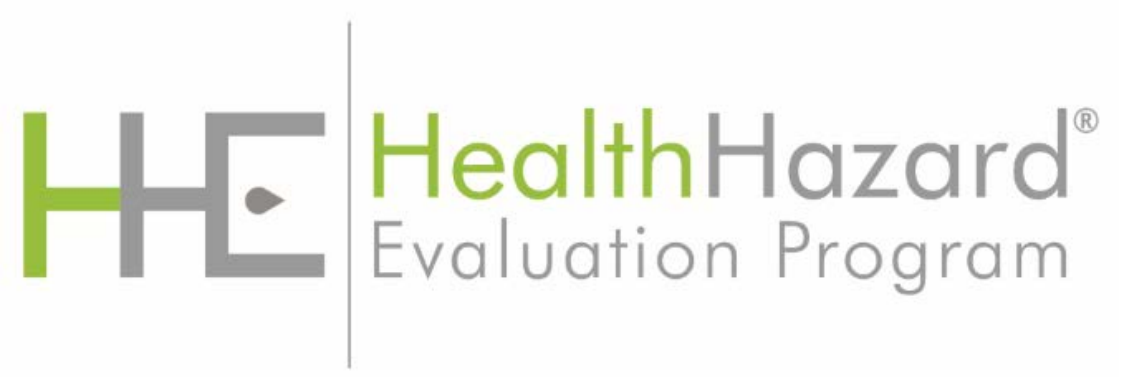

\title{
Evaluation of Workplace Exposures at a Ceramic Tile Manufacturer
}

HHE Report No. 2018-0163-3344

March 2019 


\section{Author: Gregory Burr, $\mathrm{ClH}$}

Analytical Support: Jennifer Roberts, Maxxam Analytics

Desktop Publisher: Jennifer Tyrawski

Editor: Cheryl Hamilton

Logisitics: Donald Booher, Kevin Moore, Mihir Patel

Keywords: North American Industry Classification System (NAICS) 327120 (Clay Building Material and Refractories Manufacturing), Michigan, Inorganic Acids, Ventilation, Heat Stress

\section{Disclaimer}

The Health Hazard Evaluation Program investigates possible health hazards in the workplace under the authority of the Occupational Safety and Health Act of 1970 (29 U.S.C. S 669(a)(6)). The Health Hazard Evaluation Program also provides, upon request, technical assistance to federal, state, and local agencies to investigate occupational health hazards and to prevent occupational disease or injury. Regulations guiding the Program can be found in Title 42, Code of Federal Regulations, Part 85; Requests for Health Hazard Evaluations (42 CFR Part 85).

\section{Availability of Report}

Copies of this report have been sent to the employer and employees. The state and local health departments and the Occupational Safety and Health Administration Regional Office have also received a copy. This report is not copyrighted and may be freely reproduced.

\section{Recommended Citation}

NIOSH [2019]. Evaluation of workplace exposures at a ceramic tile manufacturer. By Burr G. Cincinnati, OH: U.S. Department of Health and Human Services, Centers for Disease Control and Prevention, National Institute for Occupational Safety and Health, Health Hazard Evaluation Report 2018-0163-3344, https://www.cdc.gov/niosh/hhe/reports/pdfs/2018-0163-3344.pdf. 


\section{Table of Contents}

\section{Main Report}

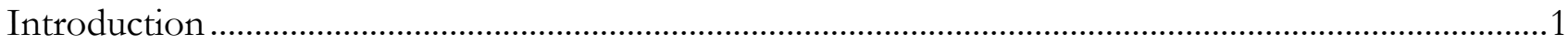

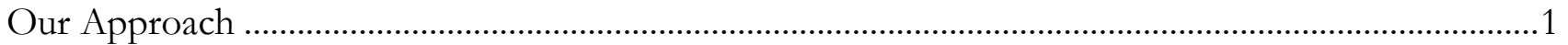

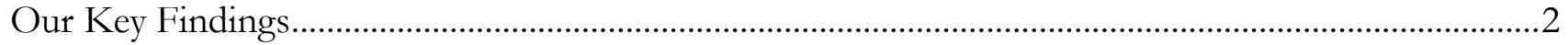

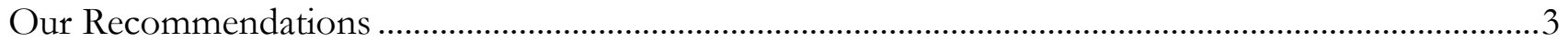

\section{Supporting Technical Information}

Section A: Workplace Information......................................................................................... A-1

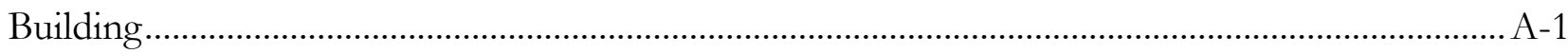

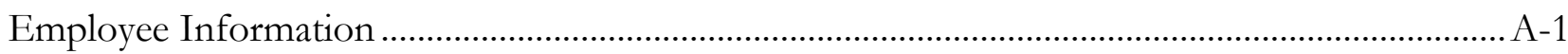

Company Concerns at This Workplace ……………………………………………............. A-1

Process Description ...................................................................................................... A-1

Section B: Methods, Results, and Discussion ………………………………………………..... B-1

Methods: Exposure Assessment ………………………………………………………... B-1

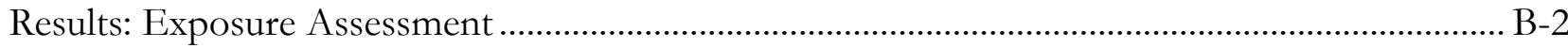

Methods: Heat Stress ........................................................................................................... B-3

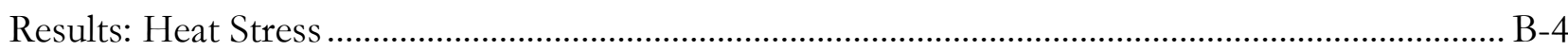

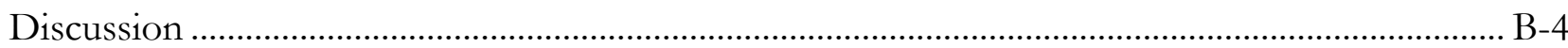

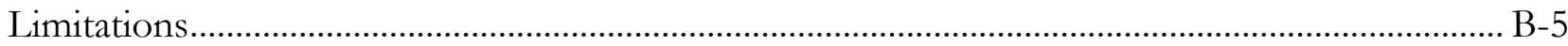

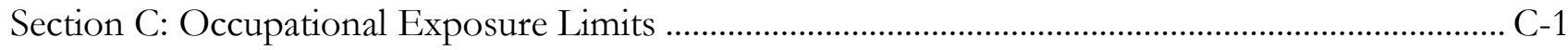

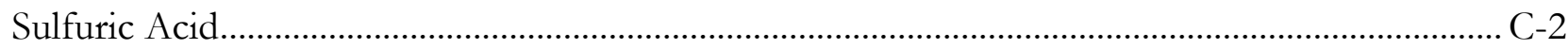

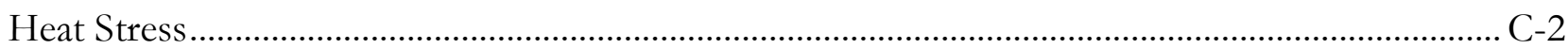

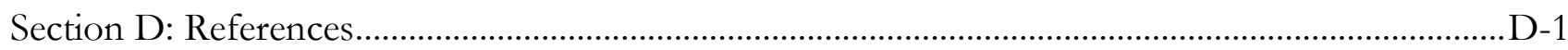


This page left intentionally blank 


\section{Introduction}

\section{Request}

We received a request from a manager at a ceramic tile manufacturer concerned about employees' potential exposures to airborne acids in the ceramic tile production area. The company manager also wondered if these acids were corroding metal surfaces and equipment in the production area.

\section{Workplace}

Making ceramic tile involved the following steps:

- Hydraulically pressing premixed clay to form tiles of varying shapes and patterns

- Drying the pressed tiles, called green ware, under controlled temperature and humidity conditions

- Bisque firing by heating tiles to approximately $1,800^{\circ} \mathrm{F}$ in electric or natural gas-fired kilns

- Hand-dipping the backs of bisque tiles in liquid paraffin to prevent absorption of glaze

- Hand glazing tiles

- Glaze firing by heating tiles to approximately $2,200^{\circ} \mathrm{F}$ in either electric or natural gas-fired kilns

- Packaging and shipping glazed tiles

At the time of our visit, about four employees routinely worked in the production area that included the dryer, kilns, waxing, and glazing. The company had one 8-hour work shift per day, Monday through Friday, and employees had flexible shift start/stop times.

\section{To learn more about the workplace, go to Section A in the Supporting Technical Information}

\section{Our Approach}

We visited the company in August 2018. On this visit we

- Observed work processes and ventilation in the tile production areas

- Collected full-shift personal and area air samples for

o sulfuric acid

0 phosphoric acid

o hydrogen chloride

o hydrogen bromide

0 nitric acid 
0 hydrofluoric acid

0 particulate fluorides

- Evaluated heat stress conditions in the production area

To learn more about our methods, go to Section B in the Supporting Technical Information

\section{Our Key Findings}

\section{Concentrations of airborne acids in the production area were low}

- Concentrations of phosphoric acid, hydrogen chloride, hydrogen bromide, nitric acid, hydrofluoric acid, and particulate fluorides were either not detected or extremely low.

- Sulfuric acid was present in all personal and area air samples.

- All personal air sample results were well below applicable occupational exposure limits.

\section{Exhaust ventilation in the production area can be improved}

- The kilns exhausted through a capped stack design (Figure 1) that impeded airflow.

- The exhaust ducts ventilating the electric kilns were too long. The ducts also had sharp bends and were connected with duct tape (Figures 2 and 3). These conditions restricted airflow.

- The canopy exhaust hood over the wax dipping station had sharp bends in the duct (Figure 4). This design blocked airflow.

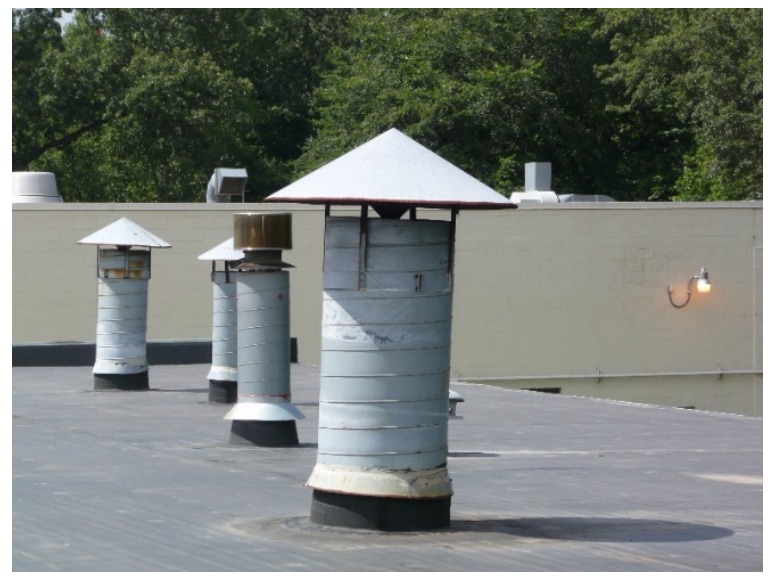

Figure 1. Rooftop capped metal exhaust stack for gas-fired kiln.

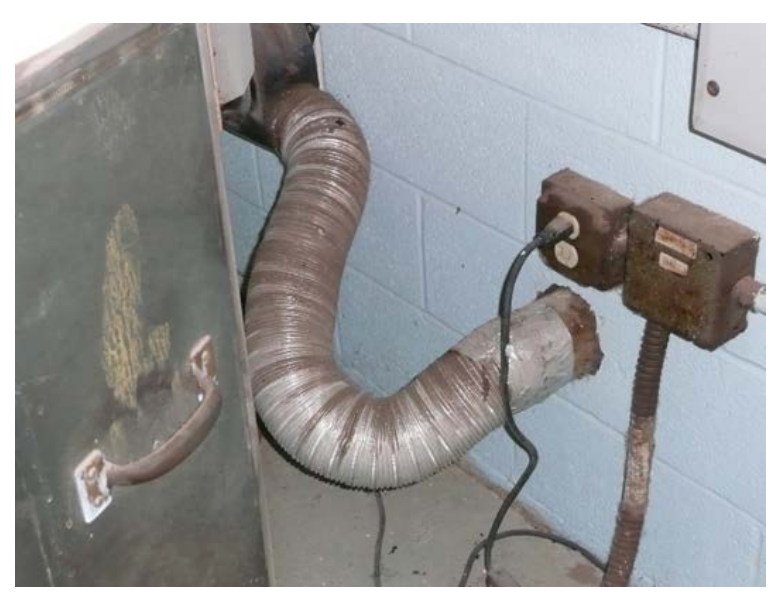

Figure 2. Excess flexible metal exhaust duct. 


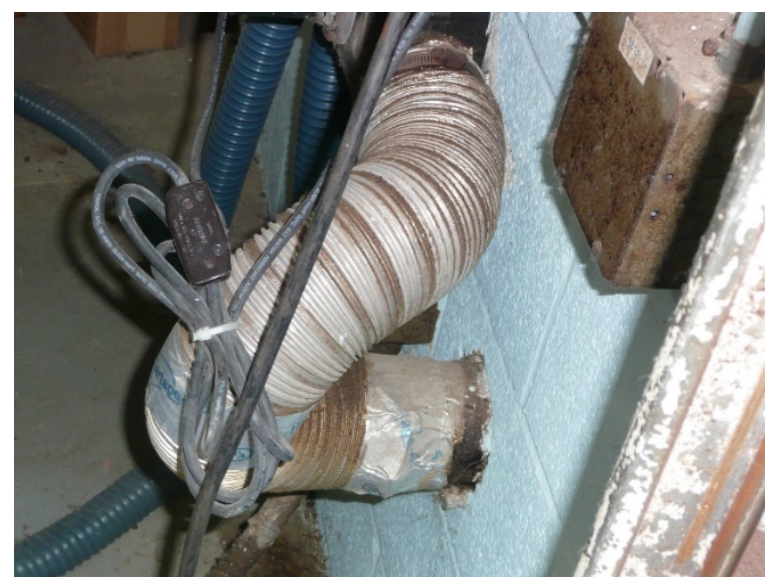

Figure 3. Flexible metal exhaust duct with a sharp bend and patched with duct tape.

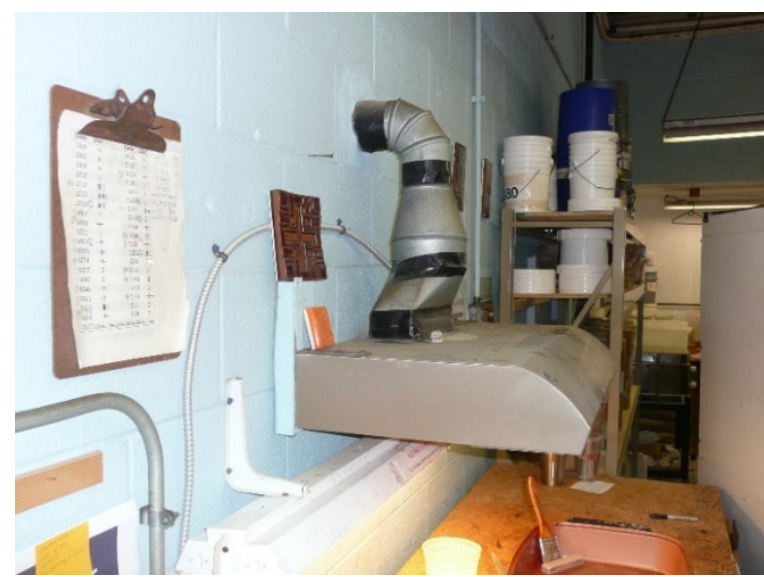

Figure 4. The hood over the paraffin wax dipping station with a $90^{\circ}$ bend in the metal exhaust duct.

\section{Potential heat stress conditions may sometimes exist during hot weather}

- The company did not have a written heat stress monitoring, training, or control program.

To learn more about our results, go to Section B in the Supporting Technical Information

\section{Our Recommendations}

The Occupational Safety and Health Act requires employers to provide a safe workplace.

Benefits of Improving Workplace Health and Safety:
$\uparrow$ Improved worker health and well-being
个 Improved image and reputation
$\uparrow$ Better workplace morale
$\uparrow$ Better products, processes, and services
$\uparrow$ Better employee recruiting and retention
$\uparrow$ Could increase overall cost savings

The recommendations below are based on the findings of our evaluation. For each recommendation, we list a series of actions you can take to address the issue at your workplace. The actions at the beginning of each list are preferable to the ones listed later. The list order is based on a well-accepted approach called the "hierarchy of controls." The hierarchy of controls groups actions by their likely effectiveness in reducing or removing hazards. In most cases, the preferred approach is to eliminate hazardous materials or processes and install engineering controls to reduce exposure or shield employees. Until such controls are in place, or if they are not effective or feasible, administrative measures and personal protective equipment might be needed. Read more about the hierarchy of controls at https://www.cdc.gov/niosh/topics/hierarchy/. 
We encourage the company to use a health and safety committee to discuss our recommendations and develop an action plan. Both employee representatives and management representatives should be included on the committee. Helpful guidance can be found in Recommended Practices for Safety and Health Programs at https://www.osha.gov/shpguidelines/index.html.

\section{Recommendation 1: Improve the Ventilation in the Production Area}

Why? Inadequate ventilation can result in unnecessary employee exposures. For example, odors are released when the paraffin on glazed tiles is burned off during glaze firing. Improving the exhaust ventilation on the gas and electric kilns will reduce volatile organic compounds and odors from entering the production areas.

How? At your workplace, we recommend these specific actions:

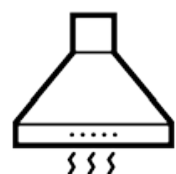

\{\}

\section{Redesign the exhaust ventilation for the gas and electric kilns}

- Eliminate sharp $\left(90^{\circ}\right)$ turns and extra length in the exhaust ducts to improve airflow.

- Replace the capped exhaust stacks with a no-loss cap design.

- Consider replacing the passive convection (natural draft) exhaust on the glazing kiln with a powered exhaust system.

- Discuss the feasibility and design of a no-loss cap design and powered exhaust system for the glazing kiln with a ventilation engineer.

\section{Recommendation 2: Start a Heat Stress Program}

Why? Preventing heat stress will reduce the risk of heat-related illness.

How? At your workplace, we recommend these specific actions:

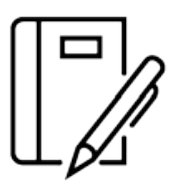

\section{A heat stress program should include}

- Providing seasonal heat stress training for employees to recognize early signs and symptoms of heat-related illnesses in themselves and their coworkers.

- Instruct employees to tell their supervisor immediately if they develop any heat-stress symptoms or if they notice any signs or symptoms in their coworkers.

- Emphasize to employees the importance of using a buddy system. 
- Allow employees to take rest breaks and intake fluids as needed. Consider supplying additional water to employees so they can wet their work clothes during the workday when temperatures are high. Wetting clothing improves evaporative cooling.

- Discourage employees from consuming large amounts of caffeine (more than six cups of coffee per day) or large amounts of sugar while working on very hot days. Some "energy drinks" may also contain caffeine.

o Caffeine may increase fluid loss and lead to dehydration.

o Drinking plain water is better to replace lost fluids. 
This page left intentionally blank 
Supporting Technic al Information

Evaluation of Workplace Exposures at a Ceramic Tile Manufacturer

HHE Report No. 2018-0163-3344

March 2019 


\section{Section A: Workplace Information}

\section{Building}

- The company is in a single-story masonry building that includes offices, showroom, design studios, and production areas. Walls separate the offices, showroom, and design studio areas from the production areas. The nonproduction areas had their own separate ventilation systems.

- The production areas includes tile pressing, drying, glazing and firing, and shipping. This area had roll-up overhead doors on two exterior walls that allowed employees to transfer raw materials and finished product into and out of the building. These doors were open during this evaluation, a typical practice during the warmer months.

\section{Employee Information}

- About four employees typically worked in the production area at time of evaluation. The employees were not unionized.

- Employees worked flexible work shifts 8-hours per day, Monday through Friday.

\section{Company Concerns at This Workplace}

- The focus of this evaluation was the production area where the green ware dryer and the electric and gas kilns were located.

- Company officials were concerned that visual corrosion evident on metal surfaces in kiln area, along with the damage to an internal humidity sensor inside the dryer, may be associated with airborne acids in the work areas.

- Officials were also concerned if airborne acids were a health concern to their employees.

\section{Process Description}

\section{Step 1: Pressing}

- The company received pallets of premixed clay (see Figure 5). Employees used a hydraulic press to form the clay to the desired shape and pattern, forming "green ware" (see Figure 6).

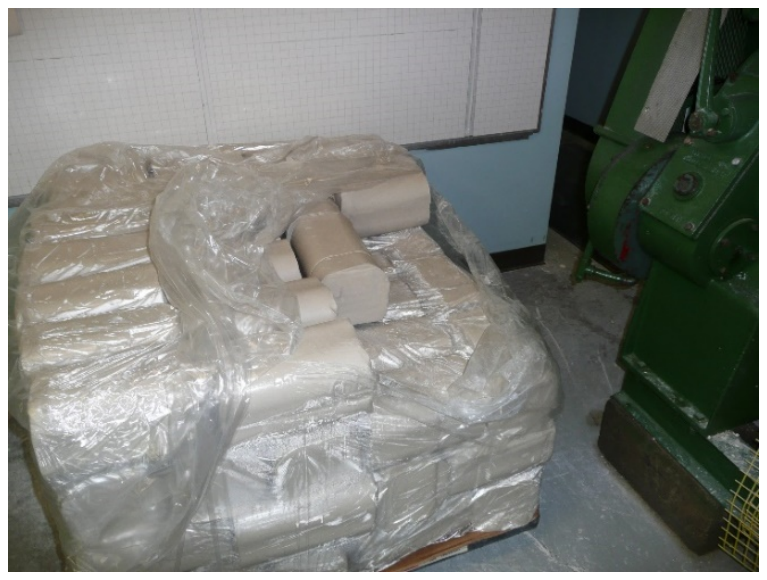

Figure 5. A pallet of premixed clay. 


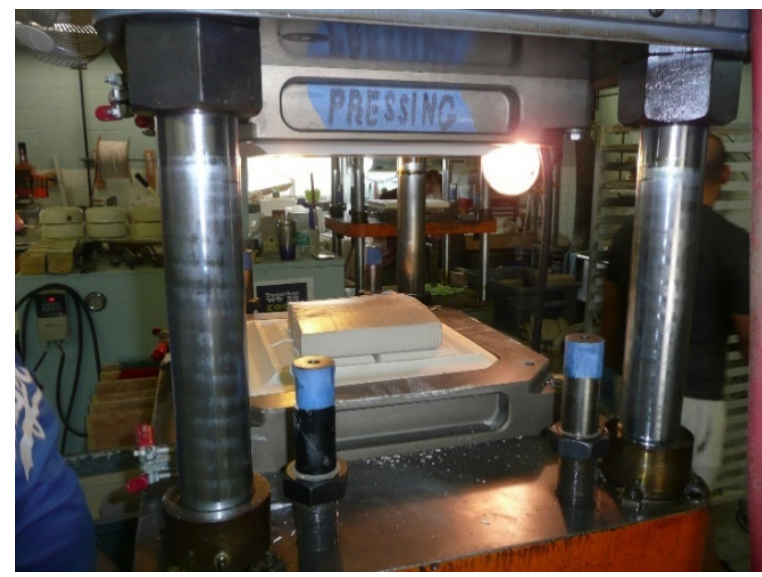

Figure 6. Hydraulic clay press holding a slab of premixed clay.

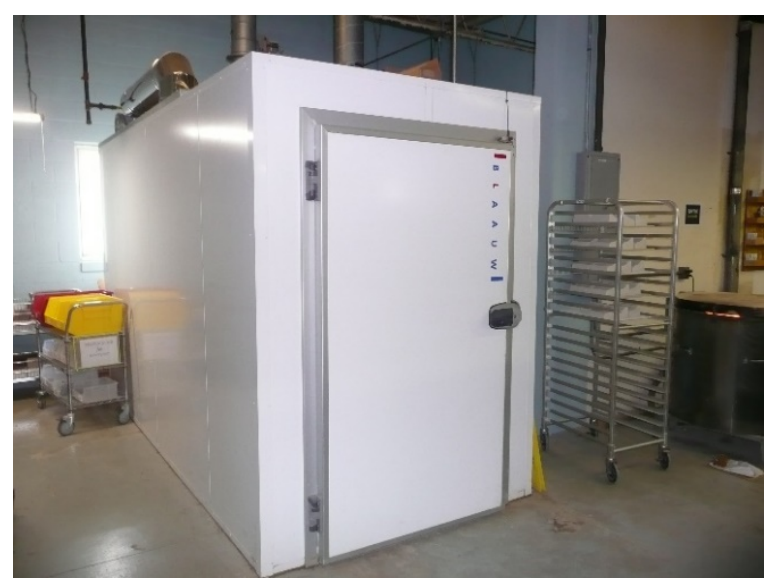

Figure 7. Enclosed gas-fired dryer.

\section{Step 2: Drying and Bisque Firing}

- Employees manually moved roller racks of green ware to an enclosed gas dryer (see Figure 7).

- The dryer slowly removed excess moisture under controlled temperature and humidity conditions. The maximum temperature reached in the dryer was $180^{\circ} \mathrm{F}$. The dryer was convection exhausted through the roof.

- Dried tiles were then heated to about $1,800^{\circ} \mathrm{F}$ in either a gas or electric kiln. This process was called "bisque firing."

\section{Step 3: Glazing, Glaze Firing, and Packaging}

- Employees manually dipped, brushed, or rolled molten wax on the parts of the bisque tiles where glaze was not wanted, typically the tile back. For this task employees heated the paraffin wax to $240^{\circ} \mathrm{F}$ using a residential-style electric skillet (see Figure 8).

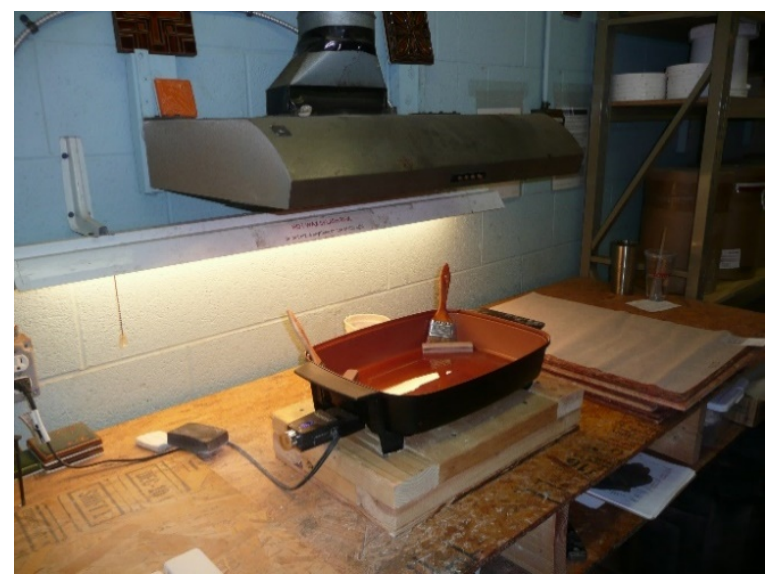

Figure 8. Paraffin wax station, consisting of an electric skillet, a brush, and a roller.

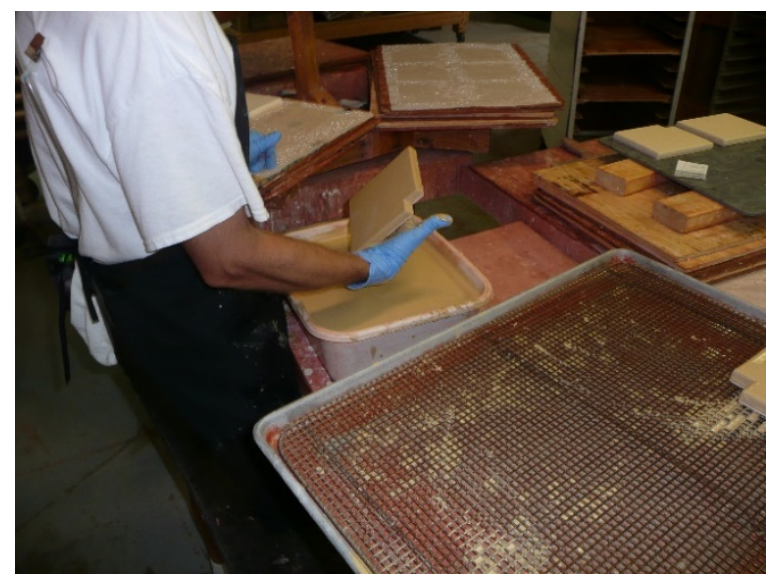

Figure 9. Employee wearing nitrile gloves hand dipping tiles into glaze.

- Employees manually glazed the entire tile by dipping (see Figure 9), or by using small brushes or pipets (for smaller, more precise patterns). 
- Glazed tiles were heated to about $2,200^{\circ} \mathrm{F}$ in a gas or electric kiln. This finishing process was called "glaze firing." The gas kiln had a convection exhaust through the roof (Figure 10); the smaller electric kilns had powered exhausts through the exterior wall (Figure 11).

- The paraffin wax (International Group, Inc.) used to coat the sections of bisque tiles where glaze was not wanted was burned off the tiles during glaze firing. Because managers and employees noticed an odor from the gas kiln during this process, the company usually performed the glaze firing overnight when fewer employees were present. However, according to employees, the odor could linger.

- The finished ceramic pieces were inspected and then stored or hand packaged for shipment.

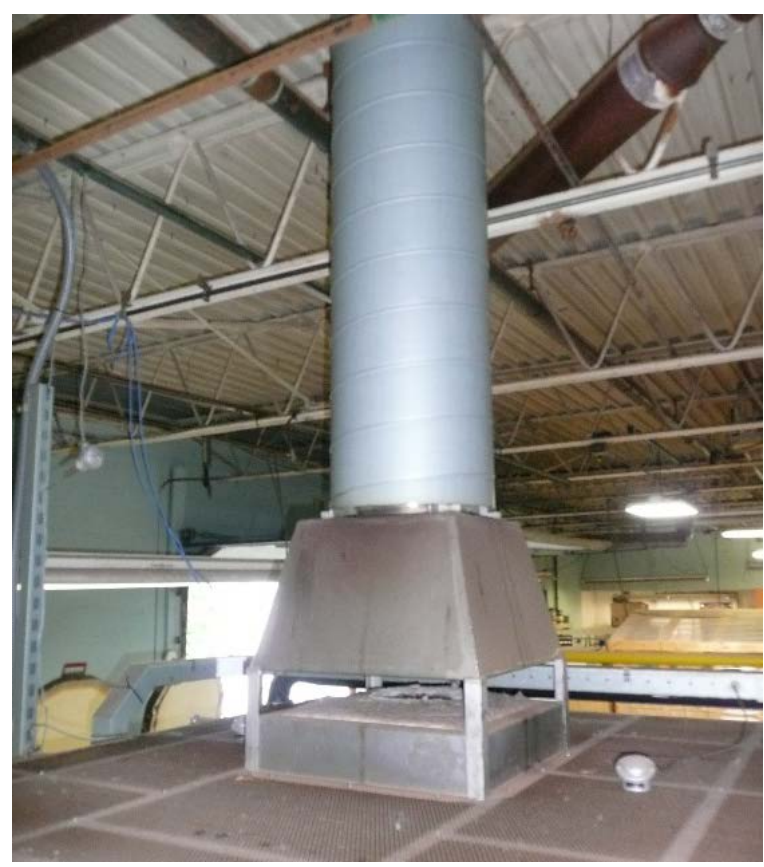

Figure 10. Rigid metal exhaust duct on top of the gas-fired kiln that extends through the roof.

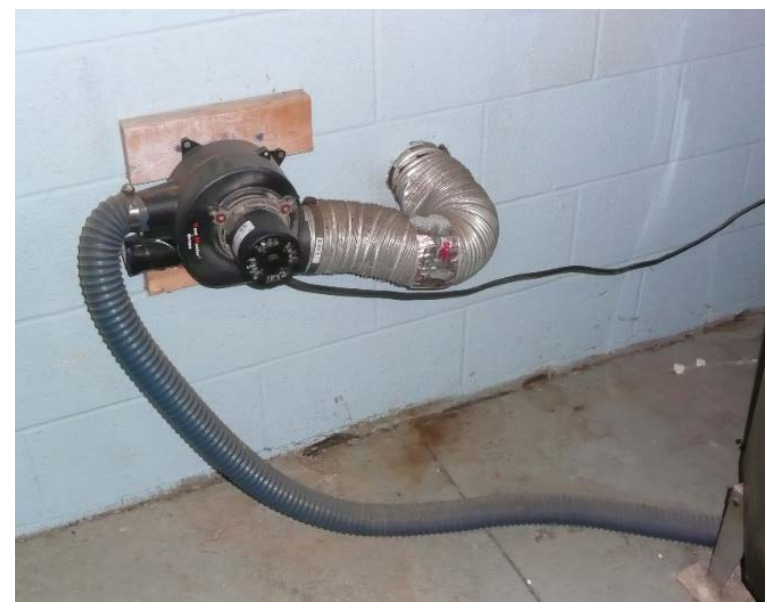

Figure 11. Flexible metal exhaust duct on an electric kiln. The duct has a sharp $90^{\circ}$ bend and is patched with duct tape. 


\section{Section B: Methods, Results, and Discussion}

We visited the company in August 2018. Our primary objectives were to

- Review prior environmental sampling conducted by the company

- Evaluate employee exposures

- Examine the exhaust ventilation visually

Because we conducted the site visit in August, we also evaluated potential heat stress conditions in the kiln area. Section $C$ provides more heat stress information.

\section{Methods: Exposure Assessment}

\section{Prior Environmental Sampling}

Prior to this National Institute for Occupational Safety and Health (NIOSH) evaluation, a company consultant collected three surface wipe samples in the production areas. These samples were taken from visible drips on the floor near the Blaaux industrial kiln, and from drips in a dryer bucket. The consultant analyzed these samples for sulfuric acid, phosphoric acid, hydrogen chloride, hydrogen bromide, nitric acid, and hydrofluoric acid.

\section{Inorganic Acids}

We collected full-shift personal air samples on three employees over 2 workdays. Over this same period, we also took full-shift area air samples in the production and tile pressing area during the work shift, as well as overnight when the company used the gas kiln to perform bisque or glaze firing.

- We analyzed the air samples for sulfuric acid, phosphoric acid, hydrogen chloride, hydrogen bromide, nitric acid, hydrofluoric acid, and particulate fluorides using the NIOSH Manual of Analytical Methods (NMAM) 7906, 7907, and 7908 [NIOSH 2019].

- We asked employees to leave their personal air sampler on during lunch unless they left the workplace. Most employees did not leave the workplace for lunch.

\section{Green Ware}

Green ware is the premixed clay (see Figures 5 and 6) prior to being dried and fired in the kiln. We collected a sample of green ware in a clear plastic screw-capped specimen jar for transport to the NIOSH laboratory. At the NIOSH lab, we tested the condensation on the inside of the specimen jar with a $\mathrm{pH}$ strip. We placed an approximately 0.75 inch square piece of green ware into a glass beaker and covered it with a watch glass. We then put the beaker on a hot plate and held it at about $183^{\circ} \mathrm{F}-185^{\circ} \mathrm{F}\left(84^{\circ} \mathrm{C}-85^{\circ} \mathrm{C}\right)$ for 24 hours. The $\mathrm{pH}$ was taken after the 24 -heating period with a $\mathrm{pH}$ strip.

\section{Paraffin Wax}

We collected a sample of unused paraffin wax (solid pellets) in a clear plastic screw-capped specimen jar for transport to the NIOSH laboratory. Because we suspected the odor in the production area was from the burning of the wax during glaze firing, we analyzed a bulk sample of the wax for VOCs and other decomposition products. Although our analytical equipment was not able to heat the wax to the highest 
temperature reached in the gas kiln $\left(2,200^{\circ} \mathrm{F}\right)$, it exceeded the boiling point of the wax. We used stainless steel thermal desorption (TD) tubes for the analyses. These tubes contain three beds of sorbent material: the first section contains Carbopack Y (90 milligrams), the second section contains Carbopack B (115 milligrams) and the last section contains Carboxen 1003 (150 milligrams). We cleaned the tubes prior to sampling by heating them at $662^{\circ} \mathrm{F}\left(350^{\circ} \mathrm{C}\right)$ for 90 minutes.

To compare an oxygenated environment to an inert one, the wax sample was prepared in two ways:

- Collecting a heated headspace sample on a TD tube

- Injecting heated air directly from the bulk wax sample into the TD system

For the heated headspace analysis, we poured about 40 paraffin pellets into a 20 -milliliter glass scintillation vial, and then covered the vial with aluminum foil. We placed the vial on a $572^{\circ} \mathrm{F}\left(300^{\circ} \mathrm{C}\right)$ hot plate and inserted a TD tube through the foil. We connected a sampling pump operating at a flow rate of about 100 milliliters per minute to draw a sample of headed headspace air through the TD tube for 2 minutes. For the direct injection analysis, we placed seven paraffin pellets inside a clean glass TD tube, placing silanized glass wool at either end of the tube to hold the heated wax pellets in place.

For both the heated headspace and direct injection analyses, we used a Markes Unity 2/Ultra automatic TD system with an internal focusing trap packed with graphitized carbon adsorbent. We connected the TD system to a gas chromatograph/mass spectrometer to identify the VOCs and other compounds using NIOSH NMAM 2549. We used a 30-meter fused silica capillary column for the analyses.

\section{Results: Exposure Assessment}

\section{Prior Environmental Sampling}

The predominate acids identified on the three surface wipe samples were hydrochloric acid, followed by sulfuric acid and hydrofluoric acid.

\section{Inorganic Acids}

Air concentrations during our evaluation were either not detected or extremely low. For example,

- Hydrochloric acid was not detected ( $<5$ micrograms per cubic meter, $\left.\left[\mu \mathrm{g} / \mathrm{m}^{3}\right]\right)$

- Hydrobromic acid was not detected $\left(<3 \mu \mathrm{g} / \mathrm{m}^{3}\right)$

- Nitric acid was not detected $\left(<1.0 \mu \mathrm{g} / \mathrm{m}^{3}\right)$

- Hydrofluoric acid was not detected $\left(<2.0 \mu \mathrm{g} / \mathrm{m}^{3}\right)$

- Phosphoric acid was not detected $\left(<0.5 \mu \mathrm{g} / \mathrm{m}^{3}\right)$

- Particulate fluoride concentrations ranged from not detected $\left(<0.5 \mu \mathrm{g} / \mathrm{m}^{3}\right)$ to $3.0 \mu \mathrm{g} / \mathrm{m}^{3}$

Detectable concentrations of sulfuric acid were measured in all of the personal and area air samples (see Table 1). However, the personal air sample results were well below the lowest applicable occupational exposure limit (OEL) of $200 \mu \mathrm{g} / \mathrm{m}^{3}$ as recommended by the American Conference of Governmental Industrial Hygienists (ACGIH) [ACGIH 2018]. 
Table 1. Airborne concentrations of sulfuric acid, expressed in $\mu \mathrm{g} / \mathrm{m}^{3}$

\begin{tabular}{|c|c|c|}
\hline Date & Location and/or activity & Sulfuric acid \\
\hline \multicolumn{3}{|c|}{ Full-shift personal air samples } \\
\hline $8 / 28 / 2018$ & Employee melting paraffin wax & 2.2 \\
\hline $8 / 29 / 2018$ & Production generalist (working near dryer and kilns) & 12 \\
\hline \multicolumn{2}{|c|}{ NIOSH recommended exposure limit (REL) } & 1,000 \\
\hline \multicolumn{2}{|c|}{ Occupational Safety and Health Administration (OSHA) permissible exposure limit } & 1,000 \\
\hline \multicolumn{2}{|c|}{ ACGIH threshold limit value } & 200 \\
\hline \multicolumn{3}{|c|}{ Full-shift area air samples } \\
\hline $8 / 28 / 2018$ & Near kilns & 4.3 \\
\hline $8 / 28 / 2018$ & Near kilns & 9.0 \\
\hline $8 / 27-28 / 2018^{*}$ & Near kilns & $4.2-4.8$ \\
\hline $8 / 28-29 / 2018^{*}$ & Near kilns & $3.5-4.0$ \\
\hline $8 / 28 / 2018$ & Clay pressing & 8.7 \\
\hline $8 / 29 / 2018$ & Near green ware dryer & 7.8 \\
\hline $8 / 28 / 2018^{*}$ & Near dryer and kilns & $4.9-8.2$ \\
\hline
\end{tabular}

*Overnight sampling times were from about 4 p.m.-12 a.m. and 12 a.m.-8 a.m.

\section{Green Ware}

The $\mathrm{pH}$ of the condensate inside the original specimen jar was 4.7. After the 24-hour heating, the $\mathrm{pH}$ of the condensate on the underside of the watch glass was also 4.7. Nothing acidic or basic was found in the analysis of the headspace of the heated green ware. For reference, tomatoes have a $\mathrm{pH}$ of 4.3-4.9, and lemon juice has a $\mathrm{pH}$ of 2.0-2.6.

\section{Paraffin Wax}

As expected, we found a wide assortment of chemicals in the wax. For example, aliphatic and aromatic hydrocarbons were present, along with chemicals having odor (ketones) or irritant (acetic acid, aldehydes) properties. The NIOSH REL for paraffin wax fume is $2,000 \mu \mathrm{g} / \mathrm{m}^{3}$. We cannot compare the bulk sample results to the NIOSH REL. However, on the basis of workplace and work practice observations, it is unlikely that personal exposures in the kiln area would exceed this limit.

\section{Methods: Heat Stress}

We used a Quest Technologies QUESTemp 36 instrument to estimate the wet bulb globe temperature (WBGT) at each work location during different times of the day. We classified metabolic workloads in the production area as rest, light, moderate, heavy, and very heavy on the basis of NIOSH and ACGIH heat stress criteria, which are the same [ACGIH 2018; NIOSH 2016]. All employees wore lightweight clothing, so no clothing adjustment to the WBGT was necessary [ACGIH 2018]. 


\section{Results: Heat Stress}

Table 2 summarizes the WBGT levels measured in the production area over 2 workdays.

Table 2. WBGT measurements in production area

\begin{tabular}{lccc}
\hline Date & Time & WBGT* $^{*}$ & Comments \\
\hline 8/28/18 & 11:00 a.m. & 78.3 & Estimated metabolic rate = light* \\
& 1:00 p.m. & 79.5 & Weather: sunny. Outdoor WBGT levels ranged \\
& 3:00 p.m. & $83.2 \dagger$ & from 81.4 (at 3:00 p.m.) to 82.8 (at 5:00 p.m.) \\
& $5: 00$ p.m. & $85.1 \dagger$ & \\
\hline 8/29/18 & $9: 00$ a.m. & 79.5 & Estimated metabolic work rate = light* \\
& $11: 00$ a.m. & 78.4 & Weather: overcast, rainy. Outdoor WBGT levels ranged \\
& $5: 00$ p.m. & 79.7 & from 75.3 (at 9:00 a.m.) to 78.6 (at 5:00 p.m.) \\
\hline
\end{tabular}

*Work included sitting with light manual work using hands or arms, or standing with some light arm work and occasionally walking. This equates to a metabolic rate of 180 Watts [ACGIH 2018].

†These values exceed the minimum ACGIH heat stress action limit of 82.4 for light, manual work.

\section{Discussion}

\section{Inorganic Acids}

We cannot determine the occupational health significance of the surface wipe sampling for inorganic acids performed prior to our evaluation because we are not aware of any criteria to interpret the results. In addition, NIOSH 7903 (the analytical method use by the consultant) is typically used to analyze air samples, not surface wipe samples. We determined that airborne concentrations of inorganic acids were not a health concern to employees because all personal sampling results were well below all applicable OELs. Likewise, the area air sampling found no (or very low) air concentrations of all of the acids tested.

We determined that acidic condensate is released from green ware during the controlled drying process. While a pH of 4.7 is not highly acidic, we do not know if this degree of acidity would be sufficient to damage or degrade painted or unpainted metal surfaces, or damage an internal electronic humidity sensor. According to company managers, the clay recipe used to make the tiles was more complex than most, containing a mixture of clays, silicates, and fluxes. We reviewed the safety data sheets for these ingredients but were not able to identify specific minerals in the clay mixture that may be responsible for the acidity.

\section{Heat Stress}

We estimated heat stress to the employees working in the kiln area on the 2 days of this evaluation by measuring the WBGT value. This value is not the same as the measured air temperature because the WBGT includes humidity, radiant heat, and wind speed to provide a more accurate index of the environmental conditions in which a person works. The WBGT value, along with the estimated work rate, can be used to determine if working conditions are approaching (or exceeding) recommended heat stress levels [ACGIH 2018].

On the basis of the WBGT levels, and assuming a light work rate, the kiln area slightly exceeded the minimum ACGIH action limit for heat stress of 82.4 on the afternoon of August 28, 2018. During this 
period, the WGBT levels ranged from 83.2 (at 3:00 p.m.) to 85.1 (at 5:00 p.m.). The ambient weather was the primary contributor to the heat stress conditions because the electric and gas-fired kilns were not operating during the workday. However, if the kilns were in operation, the WBGT levels would have been higher. Section $\mathrm{C}$ has information regarding employee training, heat stress hygiene practices, and medical surveillance, to manage these heat stress levels.

\section{Limitations}

Our evaluation had some limitations. First, industrial hygiene sampling can only document exposures on the days of sampling in the locations sampled. These results may not be representative of conditions during other days. Second, the small size and homogenous nature of the population sampled limit the statistical power and generalizability of our evaluation results. 


\section{Section C: Occupational Exposure Limits}

NIOSH investigators refer to mandatory (legally enforceable) and recommended OELs for chemical, physical, and biological agents when evaluating workplace hazards. OELs have been developed by federal agencies and safety and health organizations to prevent adverse health effects from workplace exposures. Generally, OELs suggest levels of exposure that most employees may be exposed to for up to 10 hours per day, 40 hours per week, for a working lifetime, without experiencing adverse health effects. However, not all employees will be protected if their exposures are maintained below these levels. Some may have adverse health effects because of individual susceptibility, a preexisting medical condition, or a hypersensitivity (allergy). In addition, some hazardous substances act in combination with other exposures, with the general environment, or with medications or personal habits of the employee to produce adverse health effects. Most OELs address airborne exposures, but some substances can be absorbed directly through the skin and mucous membranes.

Most OELs are expressed as a time-weighted average (TWA) exposure. A TWA refers to the average exposure during a normal 8- to 10-hour workday. Some chemical substances and physical agents have recommended short-term exposure limits ceiling values. Unless otherwise noted, the short-term exposure limit is a 15-minute TWA exposure. It should not be exceeded at any time during a workday. The ceiling limit should not be exceeded at any time.

In the United States, OELs have been established by federal agencies, professional organizations, state and local governments, and other entities. Some OELs are legally enforceable limits; others are recommendations.

- OSHA, an agency for the U.S. Department of Labor, publishes permissible exposure limits [29 CFR 1910 for general industry, 29 CFR 1926 for construction industry, and 29 CFR 1917 for maritime industry] called PELs. These legal limits are enforceable in workplaces covered under the Occupational Safety and Health Act of 1970.

- NIOSH RELs are recommendations based on a critical review of the scientific and technical information and the adequacy of methods to identify and control the hazard. NIOSH RELs are published in the NIOSH Pocket Guide to Chemical Hazards [NIOSH 2010]. NIOSH also recommends risk management practices (e.g., engineering controls, safe work practices, employee education/training, PPE, and exposure and medical monitoring) to minimize the risk of exposure and adverse health effects.

- Other OELs commonly used and cited in the United States include threshold limit values (TLVs), which are recommended by the ACGIH. The TLVs are developed by committee members of this professional organization from a review of the published, peer-reviewed literature. TLVs are not consensus standards. They are considered voluntary exposure guidelines for use by industrial hygienists and others trained in this discipline "to assist in the control of health hazards" [ACGIH 2018].

Outside the United States, OELs have been established by various agencies and organizations and include legal and recommended limits. The Institut für Arbeitsschutz der Deutschen Gesetzlichen 
Unfallversicherung (Institute for Occupational Safety and Health of the German Social Accident Insurance) maintains a database of international OELs from European Union member states, Canada (Québec), Japan, Switzerland, and the United States. The database, available at http://www.dguv.de/ifa/GESTIS/GESTIS-Internationale-Grenzwerte-für-chemische-Substanzenlimit-values-for-chemical-agents/index-2.jsp, contains international limits for more than 2,000 hazardous substances and is updated periodically.

OSHA requires an employer to furnish employees a place of employment free from recognized hazards that cause or are likely to cause death or serious physical harm (Occupational Safety and Health Act of 1970, Public Law 91-596, sec. 5[a][1]). This is true in the absence of a specific OEL. It also is important to keep in mind that OELs may not reflect current health-based information

When multiple OELs exist for a substance or agent, NIOSH investigators generally encourage employers to use the lowest OEL when making risk assessment and risk management decisions.

\section{Sulfuric Acid}

Concentrated sulfuric acid is a dense, colorless liquid that is severe irritant to the eyes, mucous membranes, and skin. Sulfuric acid mist can cause eye, nose, and throat irritation, as well as respiratory irritation [NIOSH 1974]. The extent of irritation from sulfuric acid mist depends on its concentration in the air, as well as the particle size, temperature, and relative humidity [NIOSH 1974].

The NIOSH and OSHA OELs for sulfuric acid are $1,000 \mu \mathrm{g} / \mathrm{m}^{3}$, for an 8-hour TWA, and are intended to prevent dental erosion and the irritant effects of exposure [29 CFR 1910.1000 Table Z-1; NIOSH 1974 ]. The much lower ACGIH TLV is $200 \mu \mathrm{g} / \mathrm{m}^{3}$, a limit intended to minimize pulmonary irritation as well as to prevent injury to the skin and teeth [ACGIH 2018]. Some studies have associated sulfuric acid exposure to development of laryngeal cancer [Steenland et al. 1988]. However, NIOSH, OSHA, and ACGIH have not yet designated sulfuric acid as a carcinogen.

\section{Heat Stress}

NIOSH defines heat stress as the sum of the heat generated in the body (metabolic heat) plus the heat gained from the environment (environmental heat) minus the heat lost from the body to the environment, primarily through evaporation [NIOSH 2016]. Many bodily responses to heat stress are desirable and beneficial because they help the body adapt (acclimatize) to the work environment. However, at some stage of heat stress, the body's compensatory measures cannot maintain internal body temperature at the level required for normal functioning. As a result, the risk of heat-related illnesses, disorders, and accidents increases [NIOSH 2016]. NIOSH recommends controlling total heat exposure so that unprotected healthy employees do not exceed the applicable NIOSH criteria [NIOSH 2016]. The NIOSH criterial document describes five practices to control heat stress among employees:

1. Limit or modify exposure

2. Reduce the metabolic component of the total heat load

3. Enhance employee's heat tolerance by heat acclimatization, physical conditioning, and so on

4. Train employees in safety and health procedures for work in hot environments 
5. Provide initial and periodic medical examination of employees to determine if the individual can meet the total demands and physical stresses of the job will not be placed at risk

The ACGIH heat stress guidelines use a decision-making process that considers clothing and the work rate [ACGIH 2018]. The ACGIH WBGT-based heat exposure assessment was developed for a traditional work uniform of long-sleeved shirt and pants. Also, the assessment represents conditions under which it is believed that nearly all adequately hydrated, unmedicated, healthy employees may be repeatedly exposed without adverse health effects.

While NIOSH and ACGIH guidelines can distinguish between safe and dangerous levels, professional judgment is still needed for managing a heat stress program. OSHA does not have an exposure limit for heat stress. However, OSHA does refer to the ACGIH heat stress guidance. 


\section{Section D: References}

\section{Inorganic Acids}

ACGIH [2018]. 2018 TLVs ${ }^{\circledR}$ and BEIs ${ }^{\circledR}$ : threshold limit values for chemical substances and physical agents and biological exposure indices. Cincinnati, $\mathrm{OH}$ : American Conference of Governmental Industrial Hygienists.

CFR. Code of Federal Regulations. Washington, DC: U.S. Government Printing Office, Office of the Federal Register.

NIOSH [1974]. Criteria for a recommended standard: occupational exposure to sulfuric acid. Cincinnati, OH: U.S. Department of Health, Education, and Welfare, Center for Disease Control, National Institute for Occupational Safety and Health, DHEW (NIOSH) Publication No. 74-128, https://www.cdc.gov/niosh/docs/74-128/.

NIOSH [2019]. NIOSH manual of analytical methods (NMAM). 5th ed. O'Connor PF, Ashley K, eds. Cincinnati, OH: U.S. Department of Health and Human Services, Centers for Disease Control and Prevention, National Institute for Occupational Safety and Health, DHHS (NIOSH) Publication No. 2014-151, http://www.cdc.gov/niosh/nmam.

Steenland K, Schnorr T, Beaumont J, Halperin W, Bloom T [1988]. Incidence of laryngeal cancer and exposure to acid mists. Br J Ind Med 45(11):766-776.

\section{Heat Stress}

ACGIH [2018]. 2018 TLVs ${ }^{\circledR}$ and BEIs ${ }^{\circledR}$ : threshold limit values for chemical substances and physical agents and biological exposure indices. Cincinnati, $\mathrm{OH}$ : American Conference of Governmental Industrial Hygienists.

NIOSH [2016]. Criteria for a recommended standard: occupational exposure to heat and hot environments. Cincinnati, OH: U.S. Department of Health and Human Services, Centers for Disease Control and Prevention, National Institute for Occupational Safety and Health, DHHS (NIOSH) Publication No. 2016-106, https://www.cdc.gov/niosh/docs/2016-106/. 


\section{Delivering on the Nation's promise: Promoting productive workplaces through safety and health research}

Get More Information

Find NIOSH products and get answers to workplace safety and health questions:

1-800-C DC-INFO (1-800-232-4636) | TTY: 1-888-232-6348

CDC/NIOSH INFO: cdc.gov/info | cdc.gov/niosh

Monthly NIOSH eNews: cdc.gov/niosh/eNews 